\title{
Políticas tributarias y acceso a créditos en la provincia de El Oro, sector microempresarial, periodo 2014-2019
}

\section{Tax policies and access to credit in the province of El Oro, microenterprise sector, 2014-2019 period}

\author{
Ruth Maryury Delgado-Olaya \\ Universidad Metropolitana del Ecuador, Ecuador \\ rdelgado@umet.edu.ec \\ https://orcid.org/0000-0001-7159-3729 \\ Ángel Alberto Zambrano-Morales \\ Universidad Metropolitana del Ecuador, Ecuador \\ azambrano@umet.edu.ec \\ https://orcid.org/0000-0002-7897-7327 \\ Katherine del Cisne Guamarriga-Valdez \\ Universidad Metropolitana del Ecuador, Ecuador \\ katherine.guamarriga@est.umet.edu.ec \\ https://orcid.org/0000-0002-9596-3840 \\ Paulina Esperanza Sánchez-Valle \\ Universidad Metropolitana del Ecuador, Ecuador \\ paulina.sanchez@est.umet.edu.ec \\ https://orcid.org/0000-0003-1233-3016
}

Recepción: 19/10/2021 | Aceptación: 04/01/2022 | Publicación: 10/01/2022

Cómo citar (APA, séptima edición):

Delgado-Olaya, R.M., Zambrano-Morales, A.A., Guamarriga-Valdez, K. D.C., y Sánchez-Valle

P. E. (2022). Políticas tributarias y acceso a créditos en la provincia de El Oro, sector microempresarial, periodo 2014-2019. INNOVA Research Journal, 7(1), 123-139.

https://doi.org/10.33890/innova.v7.n1.2022.1973

\section{Resumen}

La presente investigación, tiene por finalidad analizar las políticas tributarias y de acceso a créditos que contribuyen al desarrollo de las microempresas en la provincia de El Oro, período 2014-2019. 
La metodología utilizada fue cuantitativa con un enfoque descriptivo-prospectiva. La recopilación de datos se realizó a través de una revisión bibliográfica de los beneficios económicos emitidas por las políticas tributarias con relación al RISE y Régimen de Microempresas en Ecuador; revisión de las bases de datos de las páginas del Instituto Nacional de Estadísticas y Censos (INEC); la Asociación de Bancos Privados del Ecuador y el Servicio de Rentas Internas cuya información permitió un análisis comparativo entre el volumen de crédito otorgado en la provincia de El Oro y los microcréditos; asimismo, una proyección promedio de los montos concedidos a los microempresarios desde el 2016 al 2019; de igual manera se identifica la sección de mayor otorgamiento de microcréditos. Entre los hallazgos se evidenció en materia tributaria que el Régimen Impositivo Simplificado Ecuatoriano ha beneficiado a 26.912 pequeños negocios en el año 2018 pasando de la informalidad a la formalidad y la oportunidad de acceder a un crédito justificando sus ingresos. Por otra parte; la inversión en créditos concedidos por la banca privada y la SEPS; ha ido aumentando, con una excepción en el año 2019 que disminuyó. El nuevo régimen de microempresas y los altos porcentajes de interés establecidos para créditos al sector microempresarial, influyen en los flujos del disponible que se tornan indispensables para fortalecer la liquidez en las empresas, el capital de trabajo y el ingreso.

Palabras claves: microempresas; crédito; políticas tributarias.

\begin{abstract}
The purpose of this research is to analyze the tax policies and access to credits that contribute to the development of micro-enterprises in the province of El Oro, period 2014-2019. The methodology used was quantitative with a descriptive-prospective approach. The data collection was carried out through a bibliographic review of the economic benefits issued by the tax policies in relation to the RISE and the Microenterprise Regime in Ecuador; revision of the databases of the pages of the National Institute of Statistics and Censuses (INEC); the Association of Private Banks of Ecuador and the Internal Revenue Service, whose information allowed a comparative analysis between the volume of credit granted in the province of El Oro and microcredits; likewi se, an average projection of the amounts granted to microentrepreneurs from 2016 to 2019; in the same way, the section with the highest microcredit granting is identified. For the processing and interpretation of the data, the Microsoft Excel tool is used. Among the findings, it was evidenced in tax matters that the Ecuadorian Simplified Tax Regime has benefited 26,912 small businesses in 2018, going from informality to formality and the opportunity to access a credit justifying their income. On the other hand; investment in loans granted by private banks and the SEPS; has been increasing, with an exception in 2019 that decreased. The new microenterprise regime and the high interest percentages established for loans to the microenterprise sector, influence the cash flows that become essential to strengthen liquidity in companies, working capital and income.
\end{abstract}

Key words: microenterprises; credit; tax policies.

\title{
Introducción
}

El tejido empresarial representa la creación y desarrollo de empresas por medio de emprendedores que poseen una iniciativa para descubrir nuevas oportunidades de negocios. Su importancia radica al crear una empresa o emprender un negocio; asimismo, permite el crecimiento económico en una región o país, teniendo un vínculo directo con el desarrollo o aumento del 
Producto Interno Bruto (PIB) a nivel nacional; logra el avance y productividad que beneficia a las economías (Texis et al., 2016).

De las empresas en América Latina el $99.5 \%$ son mipymes, de las cuales el $88.4 \%$ corresponden a microempresas. Situación que se contrapone con el $25 \%$ de participación que generan las mipymes en la contribución del PIB en la región (Correa et al., 2018). En el informe de la (Comisión Económica para América Latina y el Caribe [CEPAL], 2020b) menciona que en las empresas en Latinoamérica, la heterogeneidad es muy alta. De esto se establece que para el año 2016 la producción del trabajo en una empresa mediana fue en promedio, menos de la mitad a una empresa grande. Por el contrario; en los negocios pequeños la producción laboral alcanzó tan solo el $23 \%$ de la producción de una empresa grande y la productividad laboral en las microempresa presentaron el equivalente al $6 \%$ con relación a las empresas grandes (p. 2).

En la organización de la productividad de los países de América Latina no existen incentivos para la ejecución de operaciones con un valor agregado, las escasas posibilidades de modernización y la informalidad que prevalece en muchos mercados laborales; que llegan hasta el $54 \%$ del empleo total, son factores que dificultan el desarrollo especialmente de la microempresas y pequeñas empresas (CEPAL, 2020b). A lo anterior se incluye, los impuestos tributarios que generan pagos que son considerados un factor negativo en los pequeños empresarios ya que disminuye el capital de trabajo y se pone en duda su destino, al no sentir que sean invertidos para mejorar la calidad de vida de los habitantes.

De este grupo, las microempresas en América Latina tendrían el mayor impacto de cierre debido a la llegada de la pandemia COVID-19 por su representación y fuerte presencia en los mercados. Las microempresas serán las más afectadas en más de 2.65 millones de cierres y las pequeñas empresas en casi 100.000 cierres. De acuerdo a su actividad económica las empresas que recibirán los golpes más fuertes de la crisis son el comercio minorista, hoteles y restaurantes (CEPAL, 2020a). Algunos microempresarios tuvieron que aplicar estrategias, como emprender en nuevos negocios, cambiando su actividad económica y condicionando la estructura empresarial a las actividades de prioridad como venta de productos de primera necesidad y suministros de bioseguridad para garantizar el ingreso familiar.

En el caso de Ecuador no será diferente ya que en el año 2018 el $90 \%$ de las empresas corresponden a microempresas; porcentaje representativo en la economía del país por su intensivo uso del factor trabajo. Al mismo tiempo, proveen del 23\% del empleo a nivel nacional, ocupando el segundo lugar después de la gran empresa. Las microempresas representan la primera opción para los ecuatorianos en generar autoempleo y emprender un negocio; por el contrario, su productividad es extremadamente baja (Instituto Nacional de Estadísticas y Censos [INEC], 2018) tan sólo generaron el $1 \%$ en ventas en relación con el total de ventas a nivel nacional. Cabe destacar, que no existen programas que orienten a los pequeños empresarios en materia tributaria, financiera y de producción, dadas las implicaciones que conlleva el crear un negocio, mantenerlo en el tiempo y hacer que se desarrolle; situación, que limita la productividad y el crecimiento en el país.

El mercado interno es el centro de actuación de las microempresas; en este sentido, su desarrollo está condicionado a políticas microeconómicas y macroeconómicas. Los aspectos inestables de la macroeconomía y caída del PIB las afectan fuertemente tanto en el nivel de 
producción como en el empleo (Dini y Stumpo, 2018). Entre los posibles obstáculos que se consideran que las afectan en su desarrollo son: la falta de una estructura única, la falta de normativas específicas que permitan delimitar sus condiciones y operatividad en el ámbito económico; por lo que, son factores que condicionan su desarrollo en el mercado.

Otro de los obstáculos al desarrollo de las microempresas son el acceso al financiamiento debido a las restricciones que se originan en los requisitos y el factor del volumen del negocio que las instituciones financieras toman en cuenta a la hora de otorgar el crédito (Cordero et al., 2019). De un estudio realizado a diez países de la región, Ecuador lidera con el $16.1 \%$ después de Colombia con restricciones al acceso a liquidez, considerándose una limitante importante a la hora de obtener un crédito (Cohen, Marcos; Baralla, 2012).

La provincia de El Oro posee una alta concentración de microempresas, éstas se encuentran registradas en el catastro del Régimen Impositivo para Microempresas y en el catastro de Régimen Impositivo Ecuatoriano, en adelante (RISE) (Servicio de Rentas Internas, 2020). En el periodo del 2018 en la provincia de El Oro están registradas 38.051 empresas en el grupo de no obligadas a llevar contabilidad y categorizadas como RISE, generaron un total en ventas de \$17.340.885; que representa el 3\% del total de las ventas a nivel nacional de estos dos grupos, como contribución a la economía en la provincia. De igual forma en este mismo año, estos dos sectores han registrado 22.102 empleo, que representan el 1\% del registro nacional de empleo (Instituto Nacional de Estadísticas y Censos, 2018). La contribución a la provincia del sector micro empresarial no obligada a llevar contabilidad tiene una representación significativa en el crecimiento y desarrollo del país.

La importancia del presente trabajo reside en analizar las políticas tributarias y de acceso al crédito que contribuyen en el desarrollo de las microempresas en la provincia del Oro, periodo 2014-2019. Para dar cumplimiento al objetivo se analiza la evolución del microcrédito en el sistema financiero del Ecuador e interpretación cuantitativa ligada al desarrollo productivo en la provincia de El Oro. Se utilizan datos relacionados con los microcréditos minorista, microcréditos de acumulación simple y microcréditos de acumulación acumulada de las cooperativas de ahorro y crédito y bancos del sistema financiero del Ecuador. Al mismo tiempo, se analizan los beneficios de las políticas tributarias originadas por el RISE y régimen de las microempresas. Esta investigación nace producto de la ejecución del proyecto de investigación "Herramientas financieras direccionado al fortalecimiento y desarrollo de las microempresas en la provincia de El Oro" de la Universidad Metropolitana del Ecuador, sede Machala.

\section{Desarrollo}

Desde las perspectivas de (Borja, 2015) la creación y crecimiento de empresas son una potencial herramienta para reducir la pobreza y elevar los ingresos que afectan en el desarrollo. Para la autora (Díaz, 2010) reconoce a la microempresa como un potencial instrumento del desarrollo en el país. Las mismas autoras declaran que el sector microempresarial podría formar parte de las estrategias de crecimiento y desarrollo de los países en la región, dada su habilidad para generar fuentes de trabajo e ingresos. De lo antes mencionado se sustenta que el diseño de políticas económicas ha tenido el propósito de influir en las microempresas. 


\section{Microempresas}

Las microempresas son pequeñas unidades económicas creadas en el entorno familiar, con la intensión de generar ingresos. Entre las principales características de las microempresas (Bukstein, 2007) se encuentran: 1) las operaciones administrativas y financieras son desarrolladas por los propietarios; 2) poseen ingresos bajos, hasta cierto rango; ya que actualmente están consideradas en este grupo según sus ingresos hasta $\$ 300.000 ; 3$ ) poseen poca productividad y baja utilización de las tecnologías; 4) los volúmenes de inversión y capital son escasos; 5) la mano de obra corresponde al ámbito familiar; y, 6) se vuelven vulnerables a cambios en el contexto en el que operan.

La misma autora presenta la clasificación de las microempresas en tres niveles según su capacidad económica financiera:

1. Microempresas de subsistencia o de supervivencia, este tipo de microempresa no generan ingresos para el ahorro, sólo para cubrir sus necesidades diarias y en ocasiones producen descapitalización; además, no proporcionan fuentes de empleo adicional.

2. Microempresas de acumulación simple, estos negocios producen en la misma magnitud de la inversión. Aquí ya se genera ahorro y costos de mano de obra.

3. Microempresas de acumulación ampliada, esta categoría comprende las empresas que generan remuneración a sus propietarios, producen utilidades y crean fuentes de empleo formalizados con el pago del salario mínimo y seguro de salud social.

En el Ecuador, a partir de la publicación del Código Orgánico de la Producción, Comercio e Inversión (2010) en adelante COPCI; y en el Reglamento para la aplicación (2011) se define a la microempresa como una unidad productiva que ejerce toda persona natural o jurídica que desarrolle actividades de producción, comercio y/o servicios y que posee entre 1 a 9 trabajadores; además, cuyo valor bruto en ventas anuales no superan los \$100.000 dólares. Por otra parte, define a la pequeña empresa como una unidad de producción que posee de entre 10 a 49 trabajadores y un valor en ventas o ingresos brutos anuales entre \$100.001,00 y \$1.000.000,00 de dólares; mientras que la empresa mediana es considerada como aquella empresa que posee entre 50 a 199 colaboradores y ventas o ingresos brutos anuales entre $\$ 1.000 .001,00$ y $\$ 5.000 .000,00$ de dólares.

\section{Políticas tributarias}

Entre los objetivos de un Estado están el uso eficiente de los recursos que; por lo general, son limitados; así como también satisfacer las necesidades de la sociedad que; por el contrario, son ilimitadas. La recaudación por concepto de impuestos constituye un instrumento para fortalecer la política fiscal en el gobierno. Los tributos son considerados ingresos que el Estado recibe de los contribuyentes como impuestos, tasas y contribuciones especiales y de mejora para solventar las necesidades básicas de la sociedad. En el Ecuador "La política tributaria promueve la redistribución y estimula el empleo, la producción de bienes y servicios, y conductas ecológicas, sociales, y económicas responsables"(Flores et al., 2019, p. 1150). El gobierno en su afán de incrementar la recaudación ha implementado estrategias como capacitaciones tributarias gratuitas, incentivos tributarios entre otros que se direccionen a una cultura tributaria en los ecuatorianos. 
En el contexto tributario las normas legales que rigen las obligaciones de los contribuyentes con el Estado están la Ley Orgánica de Régimen Tributario Interno y el Código Tributario; leyes que, han podido medir y direccionar una cultura tributaria en base a los principios de generalidad, proporcionalidad, legalidad, igualdad e irretroactividad (Salcedo y Ortega, 2020). Estos principios han sido creados con la intención de la autoridad de una educación tributaria; especialmente en los pequeños negocios. Entre los incentivos tributarios que han contribuido a regularizar y formalizar a los pequeños negocios es el RISE, creado mediante la Ley de Equidad Tributaria (2007). Entre los contribuyentes que pueden acogerse a este régimen están aquellos que generen ingresos hasta USD \$60.000 dólares cada año y posean menos de 10 empleados. Desde su creación a partir del 2008 el RISE ha incrementado cada año los inscritos en el Registro Único de Contribuyente y por ende aportan al incremento de la recaudación al corto y largo plazo (Zanzzi et al., 2016).

Beneficios que el RISE genera a las microempresas:

- No están obligadas al pago del anticipo de impuesto a la renta. Este beneficio se amplía con la Ley Orgánica de Simplificación y Progresividad Tributaria (2019) al eliminarlo para el sector del régimen de microempresas. Asimismo, quienes estén en el RISE, sus ventas no serán objeto de retención a la fuente del IVA ni de retención a la fuente del impuesto a la renta.

- Las notas de ventas o tiquetes de máquina registradora serán los comprobantes de venta que emitan ya que no se desglosa el impuesto al valor agregado. Es decir, no hay complejidad en el llenado de comprobantes de venta.

- El pago de una cuota mensual justifica a las declaraciones del impuesto al valor agregado e impuesto a la renta; de acuerdo a la actividad que realicen y del valor de sus ventas anuales informado en la administración tributaria.

- Tendrán un descuento del 5\% en la cuota mensual que cancelen por la contratación de nuevos colaboradores y que se encuentren afiliados al seguro de salud (Buestán y Araque, 2019).

Entre las disposiciones para el control y clasificación de los contribuyentes que se benefician con el RISE, la administración tributaria, establece una tabla con techos a los ingresos anuales y a la facturación mensual; clasificando 7 categorías, tal como se observa en la tabla 1. Con esta segmentación se orienta a los pequeños empresarios a ubicarse según los resultados de la actividad económica y conozcan cual es el monto máximo por el que pueden emitir la respectiva nota de venta.

Asimismo, en materia tributaria se crea la Ley Orgánica de Simplificación y Progresividad Tributaria y su reglamento de aplicación (2020) donde se establece una nueva figura de régimen micro empresarial. Dicha norma genera los procedimientos en términos tributarios que deben realizarse en la liquidación, declaración y pago del impuesto al valor agregado e impuesto a la renta. (Davalos y Jimeno, s. f.) describe la política fiscal como la que, ha liderado la estabilidad macroeconómica e incluso política en el Ecuador. Es primordial otorgar preferencias al productor e inversionista nacional; y de esta forma a pequeños y medianos productores. Estas políticas que utiliza el Estado para obtener ingresos; a través, de la recaudación de impuestos contribuyen al gasto público, aumento en la producción, estabilidad de precios y amplia las plazas de empleo. 
Tabla 1

Montos máximos en comprobantes de ventas

\begin{tabular}{|c|c|c|c|c|c|c|c|}
\hline CATEGORÍAS & 1 & 2 & 3 & 4 & 5 & 6 & 7 \\
\hline $\begin{array}{l}\text { Valores de Ingreso } \\
\text { en \$ }\end{array}$ & $0-5.000$ & $\begin{array}{l}5.001 \\
10.000\end{array}$ & $\begin{array}{r}-\quad 10.001 \\
20.000\end{array}$ & $\begin{array}{r}20.001 \\
30.000\end{array}$ & $\begin{array}{r}-30.001 \\
40.000\end{array}$ & $\begin{array}{r}-40.001 \\
50.000\end{array}$ & $\begin{array}{r}50.001 \\
60.000\end{array}$ \\
\hline $\begin{array}{l}\text { Monto máximo en } \\
\text { USD a facturar }\end{array}$ & 417,00 & 833,00 & 1667,00 & 2500,00 & 3333,00 & 4167,00 & 5000,00 \\
\hline
\end{tabular}

Fuente: (Servicio de Rentas Internas, 2021)

En la Ley de Régimen Tributario Interno (2019) en adelante (LRTI) en su artículo 9.6 establece que las microempresas nuevas tendrán la exoneración del pago en el impuesto a la renta en un plazo de 3 años a partir del primer año fiscal en el que la empresa empiece a operar. Una de las condiciones para esta exoneración implica crear empleo neto y que se utilicen productos nacionales en sus procesos de producción. De igual forma, en esta norma se describe la exoneración del impuesto a los consumos especiales en el alcohol de producción nacional o importado, así como las bebidas alcohólicas elaboradas localmente y provenientes de la fermentación alcohólica de productos agropecuarios cultivados en el Ecuador; siempre y cuando, sean adquiridos a productores artesanales, microempresarios y otros. Dentro de las condiciones a la exoneración de este impuesto contempla que contenga el 70\% de ingredientes nacionales. De forma indirecta los microempresarios son beneficiados ya que los contribuyentes que se dedican a esta actividad preferirán comprar a este sector por la exoneración a la que tendrán derecho.

En el año 2019 nace la Ley Orgánica de Simplificación y Progresividad Tributaria; de la cual no se ha escuchado muchos aspectos positivos para las microempresas referente a políticas tributarias que contribuyan al desarrollo. Entre los deberes formales que deben cumplir están las declaraciones del impuesto a la renta, impuesto al valor agregado entre otros, de forma semestral. Es decir, los valores recaudados mensualmente por concepto de impuesto al valor agregado, los microempresarios capitalizarán los negocios con dichos valores hasta la fecha establecida para su liquidación, declaración y pago.

No obstante, las declaraciones semestrales del impuesto a la renta se constituyen como un pago único del $2 \%$ lo que no permite la capitalización en los negocios, sino todo lo contrario. Los contribuyentes ven con desacierto esta política, ya que la crisis económica originada por la pandemia, ocasionó que muchos negocios cierren o cambien de actividad, esta última situación, provocó empezar una experiencia y en algunos casos desconocida. La recaudación de impuestos en el país se ha implantado como uno de los pilares primordiales del sistema económico. De acuerdo al estudio realizado por (Flores et al., 2019) el gasto fiscal real respecto al PIB real en promedio representó el 20,71\%; por el contrario, el ingreso fiscal el 18,28\%; es decir, existe un déficit fiscal estructural del 2,43\% del PIB real. En este sentido el gasto público se ha constituido en un factor decisivo para las decisiones de política fiscal y económica del Ecuador. 
Adicionalmente, se emite el Decreto Ejecutivo No. 1114 (2020) que amplía el valor de las ventas totales para formar parte del sector microempresarial; es decir, las ventas totales anuales pasan de $\$ 100.000$ dólares hasta $\$ 300.000$. Los microempresarios que cumplan esta condición serán calificados como microempresas y como beneficio no estarán obligadas a llevar contabilidad. Con la nueva normativa el cálculo para la liquidación, declaración y pago se realizará en base a las ventas brutas del ejercicio económico de manera semestral menos devoluciones, descuentos y retenciones originadas por la actividad económica que se encuentre en el régimen de microempresas. El $2 \%$ es la tasa fiscal a cancelar por concepto de impuesto a la renta. Sumado a lo anterior, las empresas que sean consideradas dentro de este régimen son objeto de retención del $1.75 \%$ en sus ventas sean por la prestación de servicios o en la comercialización de bienes. Lo que significa un mayor porcentaje por concepto de retención y por ende mayores ingresos para el Estado.

\section{Crédito microempresarial}

El Ecuador es considerado como una economía plural a nivel constitucional (Castelao Caruana, 2016). En estudios realizados por (Valentin Mballa, 2017; Ramírez y Guevara, 2021) el desarrollo interno y las microfinanzas son instrumentos para cubrir necesidades socioeconómicas de la población; en este sentido, son herramientas que fortalecen las capacidades y estrategias para complementar políticas en el desarrollo y crecimiento local. Los mismos autores identifican a las microfinanzas como servicios financieros a personas o grupos cuyo acceso a los servicios bancarios tradicionales son limitados; o a individuos cuyos ingresos económicos son bajos; no son confiables en los bancos; carecen de asesoramiento y con altas tasas de interés. El acceso a crédito tiene implicaciones en la educación por la desigualdad del ingreso, con efectos negativos en la inversión del capital humano y el desarrollo económico debido a las imperfecciones en los mercados de crédito que limitan las capacidades de los microempresarios al momento de emprender un negocio (Martínez Cuellar, 2013; Rivera y Cardozo, 2019).

Hay quienes confían casi exclusivamente en sus ahorros o sus propios ingresos obtenidos por sus negocios para financiar la inversión en las empresas, tanto al momento de crearlas como para continuar con las actividades operativas. Esto no quiere decir, que nunca recurren a fuentes externas; pero, cuando lo hacen, recurren casi siempre a fuentes informales, tales como familia, amigos, y prestamistas no oficiales. Para los microempresarios los bancos, cooperativas entre otros, no son reconocidas como fuentes positivas o de primera opción, allí es donde radica el problema de la poca expansión de las microempresas ya que el confiar solo en sus ingresos o del financiamiento informal limita notablemente su crecimiento (Hernández et al., 2019).

Los microcréditos en Ecuador están clasificados en 3 tipos, detallados por la Junta de Política y Regulación Monetaria y Financiera del Ecuador (2015) en la resolución No. 043-2015F, como segmentos de créditos: Los créditos solicitados en un valor menor a los mil dólares americanos se consideran microcrédito minorista. En cambio, los créditos solicitados desde los mil dólares americanos hasta diez mil dólares americanos estarán en el tipo de microcrédito de acumulación simple. Por el contrario, los créditos superiores a los diez mil dólares están en el segmento de microcréditos de acumulación acumulada. 
Al mismo tiempo, para el sector microempresarial, la tasa promedio de crédito supera el $20 \%$ sean en las instituciones financieras como bancos o cooperativas; por el contrario, la inflación no supera el 4\%; es decir, la tasa real activa establecida es más del 16\% (Vásquez Salinas, 2011). El efecto real del microcrédito se vincula con el capital de trabajo; ya que contablemente es el resultado de la diferencia entre el activo corriente y el pasivo corriente; dando como resultado el disponible necesario para emprender un negocio. En el estudio realizado por (Calle y Calle, 2011) se evidencia en Ecuador que los microempresarios necesitan liquidez para operar y que el capital de trabajo causa los efectos en el desarrollo económico; estos, vinculados a las políticas que apoyan las líneas de crédito. En este sentido las empresas tienen como finalidad obtener rentabilidad y liquidez suficiente para cubrir con sus obligaciones a corto plazo y desarrollarse en una estructura sólida y solvente económicamente al largo plazo.

Para el acceso a un crédito la documentación solicitada por las instituciones del sistema financiero, más comunes son: cédula de identidad, certificado de votación del deudor, cónyuge y garantes, copia de un documento de servicio básico como agua, luz teléfono u otros tanto del deudor, cónyuge y garantes. Sumado a lo anterior tener un negocio o emprendimiento mínimo de 6 meses. Entre los objetivos del Estado ecuatoriano están mejorar la calidad de vida de sus mandantes; el microcrédito es una política en materia económica y una herramienta que busca cristalizar dicho objetivo; es decir, apoyar a los pequeños negocios y en especial a las familias excluidas y que no poseen oportunidad para desarrollarse.

La aplicación del RISE logró formalizar a 724.161 microempresarios de forma voluntaria al sistema nacional tributario; es decir, inscribir el 40,43\% del total de contribuyentes activos en el registro único de contribuyente (RUC) al 21 de noviembre del 2018; con facilidades del pago por impuestos y legalizando a los pequeños negocios que se encontraban en la informalidad. La formalidad permite a los pequeños empresarios cumplir con uno de los requisitos que solicitan las instituciones financieras a los contribuyentes independientes como es el Régimen Único de Contribuyente (RUC) (Endara y Villacís, 2018).

El pago mensual a través de una cuota es la modalidad en el RISE; la cual, reemplaza la liquidación, declaración y pago del impuesto al valor agregado y del impuesto a la renta tal como se observa en la tabla 2; con la presentación de la cédula de identidad del contribuyente en una institución financiera a nivel nacional. Los pequeños negocios adscritos al RISE, en la provincia de El Oro para el año 2018, son alrededor de 26.809 dicha cifra corresponde al $6 \%$ de pequeñas empresas a nivel nacional y que venden a consumidores finales. La administración tributaria recaudó \$ 83.226,00 por concepto de impuestos del RISE en los años 2016, 2017, 2018 y 2019 (Servicio de Rentas Internas, 2019).

\section{Tabla 2}

Cuotas RISE 2017-2019

\begin{tabular}{|c|c|c|c|c|c|c|c|c|c|}
\hline $\begin{array}{l}\text { Ingresos } \\
\text { promedio }\end{array}$ & anuales & $\begin{array}{l}\text { De 0 } \\
5.000\end{array}$ & $\mathbf{a}$ & $\begin{array}{l}\text { De } 5.001 \text { a } \\
10.000\end{array}$ & $\begin{array}{l}\text { De } 10.001 \\
\text { a } 20.000\end{array}$ & $\begin{array}{l}\text { De } 20.001 \\
\text { a } 30.000\end{array}$ & $\begin{array}{l}\text { De } 30.001 \\
\text { a } 40.000\end{array}$ & $\begin{array}{l}\text { De } 40.001 \\
\text { a } 50.000\end{array}$ & $\begin{array}{l}\text { De } 50.001 \\
\text { a } 60.000\end{array}$ \\
\hline \multicolumn{10}{|c|}{ Actividades } \\
\hline Comercio & & 1.43 & & 4.29 & 8.59 & 15.74 & 21.48 & 28.62 & 37.21 \\
\hline
\end{tabular}


Ruth Maryury Delgado-Olaya, Ángel Alberto Zambrano-Morales, Katherine del Cisne Guamarriga-Valdez y Paulina Esperanza Sánchez-Valle

ISSN 2477-9024. Innova Research Journal (Enero-Abril, 2022). Vol. N7, No. 1, pp. 123-139

\begin{tabular}{lllllllll}
\hline $\begin{array}{l}\text { Ingresos } \\
\text { promedio }\end{array}$ & anuales & $\begin{array}{l}\text { De } \\
\mathbf{5 . 0 0 0}\end{array}$ & $\begin{array}{l}\text { a } \\
\text { De 5.001 a } \\
\mathbf{1 0 . 0 0 0}\end{array}$ & $\begin{array}{l}\text { De 10.001 } \\
\mathbf{a 2 0 . 0 0 0}\end{array}$ & $\begin{array}{l}\text { De 20.001 } \\
\text { a 30.000 }\end{array}$ & $\begin{array}{l}\text { De 30.001 } \\
\mathbf{a ~ 4 0 . 0 0 0}\end{array}$ & $\begin{array}{l}\text { De 40.001 } \\
\mathbf{a 0 . 0 0 0}\end{array}$ & $\begin{array}{l}\text { De 50.001 } \\
\text { a 60.000 }\end{array}$ \\
\hline Servicio & 4.29 & 22.90 & 45.80 & 85.87 & 130.24 & 178.49 & 257.62 \\
Manufactura & 1.43 & 7.17 & 14.31 & 25.77 & 35.79 & 45.80 & 64.41 \\
Construcción & 4.29 & 15.74 & 32.92 & 61.54 & 87.31 & 135.97 & 193.22 \\
Hoteles y Restaurantes & 7.17 & 27.19 & 54.39 & 94.46 & 150.28 & 206.10 & 260.48 \\
Transporte & 1.43 & 2.86 & 4.29 & 5.72 & 18.66 & 38.64 & 70.13 \\
Agrícolas & 1.43 & 2.86 & 4.29 & 7.17 & 11.45 & 17.17 & 21.48 \\
Minas y canteras & 1.43 & 2.86 & 4.29 & 7.17 & 11.45 & 17.17 & 21.48 \\
\hline
\end{tabular}

Fuente: (Servicio de Rentas Internas, 2021)

\section{Metodología}

La investigación tiene un enfoque cuantitativo, no experimental, de tipo descriptivaprospectiva. El estudio es de corte longitudinal ya que se analizan datos en un período de tiempo. No existe manipulación de las variables inmersas en este contexto, se limita a observar estos hechos tal como se dan en su contexto natural (Sampieri et al., 2014). La unidad de análisis es el sector microempresarial de la provincia de El Oro, período 2014-2019. La recopilación de datos se realizó a través de una revisión bibliográfica de los beneficios económicos emitidas por las políticas tributarias con relación al RISE y Régimen de Microempresas en Ecuador. Al mismo tiempo se revisó las bases de datos de las páginas del Instituto Nacional de Estadísticas y Censos (INEC); la Asociación de Bancos Privados del Ecuador y el Servicio de Rentas Internas cuya información permitió un análisis comparativo percentil entre el volumen de crédito otorgado en la provincia de El Oro y los microcréditos; asimismo, una proyección promedio de los montos concedidos a los microempresarios desde el 2016 al 2019; de igual manera se identifica la sección de mayor otorgamiento de microcréditos. Para el procesamiento e interpretación de los datos se utiliza la herramienta Microsoft Excel.

\section{Resultados y Discusión}

Se proyecta para el año 2020 la recaudación tributaria, como primer período de aplicación del $2 \%$ de impuestos por concepto de pago del impuesto a la renta de los contribuyentes categorizados como microempresas; cuya base imponible son las ventas generadas; tomando como ejemplo a la provincia de El Oro en el año (2019) período en el cual las personas naturales no obligadas a llevar contabilidad del sector comercio tipo G, tuvieron ventas de $\$ 5.844 .870,00$ dólares; menos el 17\% en que disminuyó el primer semestre del 2020 (Primicias, 2020) los resultados demuestran que la recaudación será aproximadamente de $\$ 97.024,84$; es decir, un promedio de $\$ 6,38$ dólares tendría que cancelar cada microempresa; considerando las 15.185 existentes en el año 2018. Para este ejemplo no se descartaron las actividades que no deben ser incluidas en el régimen de microempresas.

El pago del $2 \%$ por concepto de impuesto a la renta a microempresas es considerado (Nacata y Monge, 2021) un incremento significativo al comparar el régimen general con el actual. 
Este impuesto se puede catalogar como el impuesto a los ingresos ya que no se considera la deducibilidad de los costos y gastos generados en la actividad económica que generalmente son alto.

Como se observa en la figura 1; el segmento de microcrédito minoristas en el período de estudio ha tenido una tendencia decreciente del -86.37\% desde el 2016 hasta el 2019. En cambio; para los microcréditos de acumulación simple hay una tendencia positiva en el año 2017; no obstante, en los dos últimos años decrecen hasta un $-10 \%$. Por el contrario, en el segmento de acumulación ampliada tiene una tendencia positiva en los años 2016 al 2018; mientras para el año 2019 se muestra una pequeña disminución. El mayor otorgamiento de créditos se refleja en el segmento de microcréditos de acumulación ampliada con \$281,48 millones de dólares seguido de microcréditos de acumulación simple con \$226,32 millones de dólares y el segmento minorista con $\$ 9,81$ millones de dólares. Las cifras muestran los resultados de acuerdo a la aplicación del monto de crédito; ya que los minoristas pueden acceder hasta \$1.000,00 dólares; mientras que los de acumulación ampliada pueden acceder por montos superiores a \$10.000,00 dólares.

Las políticas fiscales deben dirigirse a la demanda y el financiamiento a prestatarios solventes y pérdidas por cambios en aspectos macroeconómicos por parte de los prestatarios y prestamistas; es decir, políticas que contribuyan al desarrollo y crecimiento de los agentes que solicitan prestado incluidos pequeños y medianos empresarios (Levy, 2013). Del estudio realizado se establece que los microempresarios tienen acceso a créditos de la banca privada; sin embargo, es necesario una mayor consideración a los entes del microcrédito minorista para que este sector logre una mayor consolidación en el tiempo. Se puede señalar (Sumba y Santistevan, 2018) que los recursos financieros y altas tasas de interés limitan la adquisición de productos y recurso humano calificado ocasionando que no se desarrollen y que no se mantengan en el largo plazo.

\section{Figura 1}

Comportamiento del microcrédito en la provincia de El Oro

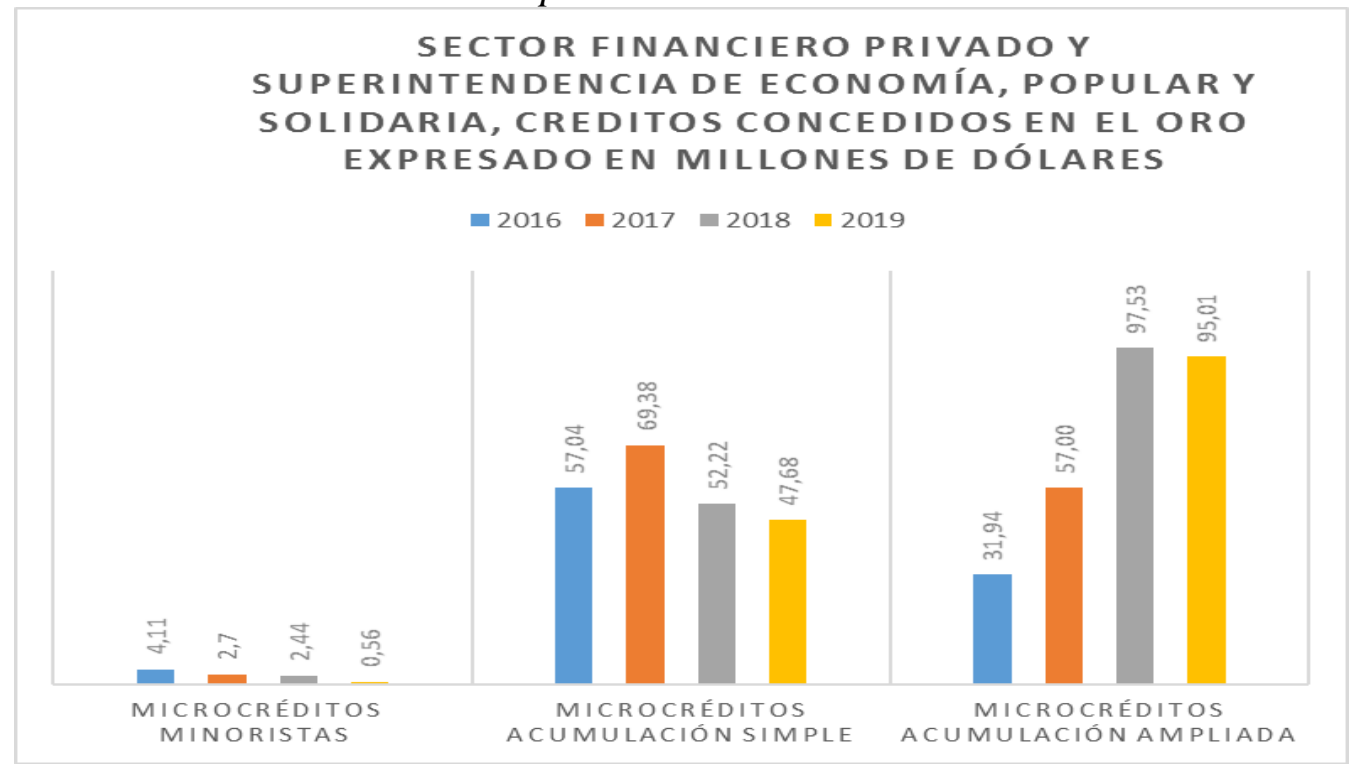

Fuente: (Asociación de Bancos Privados del Ecuador, 2019b) 
La inversión del sistema financiero privado y la SEPS, como se observa en la figura 2; en la provincia de El Oro ha ido aumentando entre los años 2016 al 2019 en un 40\%; esto debido a las condiciones de la provincia al desarrollar actividades agropecuarias en un $23.5 \%$; comercio $19.4 \%$ y actividades inmobiliarias en un $6.2 \%$ (2019a). De la cartera de crédito total destinada a la provincia de El Oro \$600,75; \$822,89; \$1012,21 y \$1036, 44 millones entre los años 2016 al 2019 respectivamente; se han destinado aproximadamente a microcréditos el $15 \%$ del total de inversión en los años 2016 al 2018; existe una pequeña disminución para el año 2019 del 2\%; es decir, la inversión aproximada del 13\%. Para (Urdaneta Montiel et al., 2020, como se citó en Tafur Saiden 2009) los créditos que otorga el sistema financiero tienen un impacto directo en el crecimiento económico ya que son una medida eficaz para impulsar las pequeñas y medianas empresas. El porcentaje estimado del microcrédito se considera insuficiente considerando la magnitud de las microempresas que representan en la provincia de El Oro; por ello, en la revisión de la literatura se establece que el acceso a financiamiento es una causa que limita el desarrollo empresarial.

\section{Figura 2}

\section{Comportamiento del microcrédito vs la cartera de crédito}

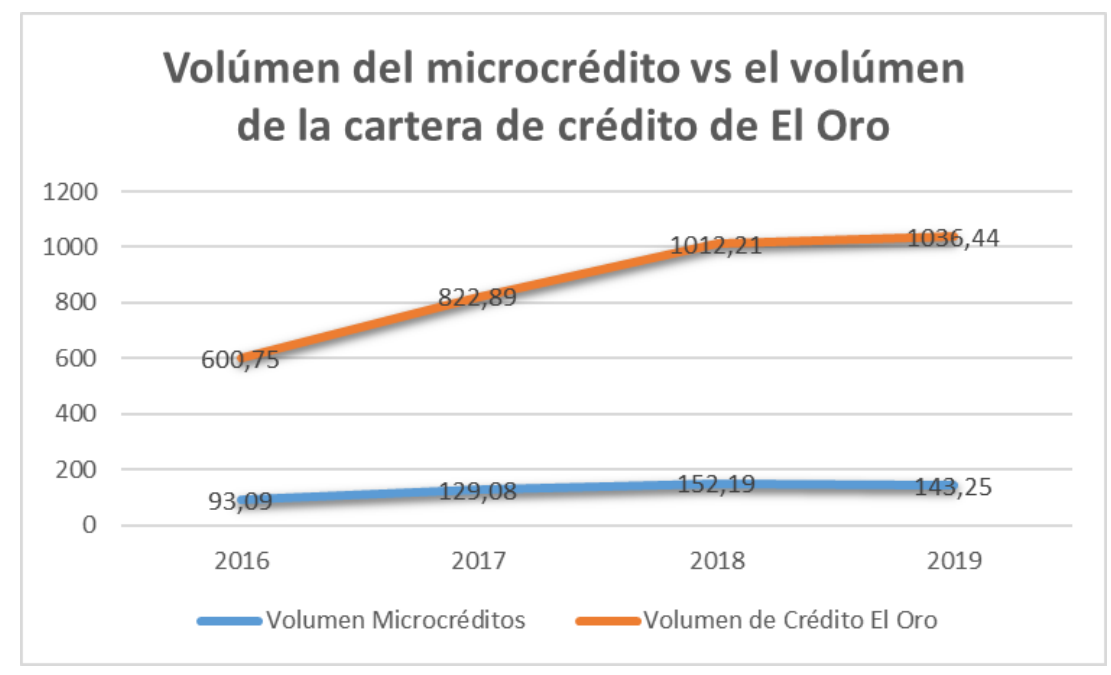

Fuente: (Asociación de Bancos Privados del Ecuador, 2019b).

De acuerdo a la proyección realizada, como se observa en la tabla 3, las instituciones financieras privadas y la SEPS han concedido microcréditos en la provincia de El Oro; en promedio a cada microempresa en $\$ 2.369,18$ en el año 2016; en el año $2017 \$ 3.176 .02$; en el año $2018 \$ 3.799,53$ y en el año $2019 \$ 3.650,52$. Cabe mencionar que las microempresas en este sector sur del país ocupan el segundo lugar en generar empleo después de la pequeña empresa; ya que en los años del 2016 al 2018 generaron un promedio de 26.000 empleos, mientras que en el año 2019 son las primeras en generar empleo en 28.463. Por el contrario; las ventas son las que menor representatividad tienen frente a la pequeña, medianas y gran empresa (Instituto Nacional de Estadísticas y Censos, 2018). En este sentido el capital de trabajo es afectado a menudo por la limitación del financiamiento, en los que hay alta dependencia en crédito y tasas de interés fuera 
del equilibrio de mercado, situación que se corresponde al caso en Ecuador (Herrera, 2015, como se citó en Kumar, 2004).

Tabla 3

Créditos concedidos a las microempresas en la provincia de el oro

\begin{tabular}{lrrr}
\hline Período & \multicolumn{1}{l}{$\begin{array}{l}\text { Volumen } \\
\text { Microcréditos }\end{array}$} & $\begin{array}{c}\text { Número } \\
\text { Microempresas }\end{array}$ & $\begin{array}{l}\text { Promedio } \\
\text { en } \\
\text { Crédito }\end{array}$ \\
\hline 2019 & 143.250 .000 & 39.241 & $3.650,52$ \\
2018 & 152.190 .000 & 40.055 & $3.799,53$ \\
2017 & 129.080 .000 & 40.642 & $3.176,02$ \\
2016 & 93.090 .000 & 39.292 & $2.369,18$ \\
\hline
\end{tabular}

Fuente: (Asociación de Bancos Privados del Ecuador, 2019b) y (Servicio de Rentas Internas, 2019).

Otro aspecto relevante en los créditos concedidos por el sistema financiero son las tasas activas efectivas referencial que establece el Banco Central del Ecuador (2021) en el segmento de microcréditos a minoristas, a diciembre del 2019 se ubican entre el 20\% y el 25,18\%; representa la tasa más alta del sistema financiero. Las tasas de interés están determinadas por la estructura de las empresas; es decir, el tamaño, un ejemplo es la condición del sector micro empresarial; en otro sentido, al hablar de mayores volúmenes de crédito y menores tasas de interés los microempresarios tendrían la oportunidad de mejorar su desempeño empresarial (Castillo Polanco, 2013). En el estudio realizado por (Astorga y Morillo, 2010) los techos a las tasas de interés activas que cobran las instituciones financieras han generado disminución en el acceso a créditos para personas y empresas pequeñas o medianas. De la literatura revisada, cuando ocurre esta situación, los prestatarios que no tienen oportunidad de un crédito en el sistema financiero acuden a mercados informales con tasas mayores. En términos financieros para acceder a un crédito depende de la capacidad de la empresa para cancelarlo; es decir, mayor capacidad menor riesgo.

\section{Conclusiones}

El Régimen Impositivo Simplificado Ecuatoriano, ha logrado legalizar a 26.912 pequeños negocios que obtienen ventas hasta $\$ 60.000$ dólares americanos, entre las ventajas que lo destacan están no cancelar costos por honorarios profesionales por declaraciones y justificar los ingresos provenientes de actividades económicas lícitas, condición para acceder a un crédito.

Con el nuevo Régimen de Microempresas se incorpora una nueva modalidad de cálculo del impuesto a la renta del $2 \%$ en los negocios de este régimen, considerado un desembolso de dinero que disminuye el capital de trabajo y que significa un pago único al no permitir deducir los costos y gastos que ocasiona la actividad económica. Se puede señalar que es necesario la simplificación del pago de impuestos para que los negocios pequeños se motiven a formalizarse y 
que no ocupen de profesionales para cumplir con sus obligaciones tributarias, disminuyendo la evasión tributaria que sería otro tipo de investigación relacionado a este sector.

Los resultados de la proyección de los créditos pueden considerarse insuficientes ya que una de las desventajas de los pequeños negocios son los altos costos que ocasionan sus reducidas adquisiciones; así como también sus altos costos de operación con relación a su tamaño. Se recomienda una mayor bancarización, acompañamiento financiero y estructural a fin de que se note el efecto del crédito otorgado, ganando ambos sectores el microempresarial y el sistema financiero.

Las altas tasas de interés en los créditos para el sector microempresarial; influye en el flujo de caja, disminuyendo el capital de trabajo e ingresos que necesitan las empresas para disminuir el riesgo de iliquidez; lo que desfavorece los incentivos al sector micro productivo. Los hallazgos dan pautas hacia donde deben dirigirse las políticas tributarias si se tiene la intención de incentivar al sector microempresarial, que como se demostró son el motor para disminuir el desempleo y generar ingresos económicos. Por el contrario, no se obtienen conclusiones de cómo solucionar estas carencias que acoge al sector.

\section{Referencias bibliográficas}

Asamblea Nacional República del Ecuador. (2010). Código Orgánico de la Producción, Comercio $e \quad$ Inversiones, COPCI. https://www.correosdelecuador.gob.ec/wpcontent/uploads/downloads/2018/11/COPCI.pdf

Asamblea Nacional República del Ecuador. (2011). Reglamento de Inversiones del Código Orgánico de la Producción. Servicio de Rentas Internas, Decreto Ejecutivo 757. https://bit.ly/3t1UMJc

Asamblea Nacional República del Ecuador. (2019). Ley Orgánica de Simplificación y Progresividad Tributaria. https://bit.ly/3Hy1pXR

Asamblea Nacional República del Ecuador. (2020). Reglamento para la Aplicación a la Ley Orgánica de Simplificación y Progresividad Tributaria. Servicio de Rentas Internas. https://bit.ly/3HzOKUm

Asociación de Bancos Privados del Ecuador. (2019a). La Banca en Ecuador. Un enfoque provincial.

Asociación de Bancos Privados del Ecuador. (2019b). www.asobanca.org.ec/. https://datalab.asobanca.org.ec/datalab/resources/site/index.html?QlikTicket=W3SdgLtX HXicf4YzV\#

Astorga, A., y Morillo, J. (2010). Acceso al Crédito en el Ecuador; Retorno a la Represión Financiera? Centro de Investigaciones Económicas Universidad de las Américas. https://www.udla.edu.ec/wp-content/uploads/2013/12/1432011124Acceso-al-credito-enel-Ecuador.pdf

Banco Central del Ecuador. (2021). Tasas de Interés. www.bce.gob.ec. https://contenido.bce.fin.ec/documentos/Estadisticas/SectorMonFin/TasasInteres/TasasVi gentes122019.htm

Borja, L. A. (2015). Las Microempresas comerciales Categoría Tributaria en la Ciudad de 
Machala. Un estudio desde la mirada de los microempresarios. http://repositorio.utmachala.edu.ec/handle/48000/6871

Gualotuña, J. C., y Araque, F. G. (2019). Régimen Impositivo Simplificado Ecuatoriano, como Mecanismo para Disminuir la Informalidad en los Centros Comerciales del Ahorro del Distrito Metropolitano de Quito [Tesis de maestría, Universidad Politécnica Salesiana sede Quito]. https://dspace.ups.edu.ec/bitstream/123456789/16883/1/UPS-QT13216.pdf

Bukstein, G. (2007). Economías locales y Redes Asociativas. Ediciones de la Fundació Càtedra Iberoamericana, Universitat de les Illes Balears. http://ibdigital.uib.es/greenstone/collect/fundacioCatedraIberoamericana/archives/gabriel a.dir/gabrielaBukstein.pdf

Calle, J., y Calle, D. (2011). Evaluación del impacto socioeconómico del microcrédito en la zona oriental de la provincia del Azuay. Retos. Revista de Ciencias de la Administración y Economía, 1(1), 11-18. https://doi.org/10.17163/ret.n1.2011.01

Castelao Caruana, M. E. (2016). Las políticas públicas y su visión de la economía social y solidaria en Argentina. Revista Mexicana de Ciencias Politicas y Sociales, 61(227), 349-378. https://doi.org/10.1016/S0185-1918(16)30032-0

Castillo Polanco, L. A. (2013). Determinantes del desempeño de la tecnología del microcrédito individual. Investigacion Economica, 72(285), 115-140. https://doi.org/10.1016/S01851667(13)72598-0

Cohen, Marcos; Baralla, G. (2012). La situación de las PyMEs en América Latina. IERAL, de Fundación Mediterránea, 114, 1-25. https://www.ieral.org/images_db/noticias_archivos/2157-La situación de las PyMEs en América Latina.pdf

Comisión Económica para América Latina y el Caribe (CEPAL). (2020a). Enfrentar los efectos cada vez mayores del COVID-19 para una reactivación con igualdad. En Informe Especial Covid-19 (Vol.

5). https://repositorio.cepal.org/bitstream/handle/11362/45782/4/S2000471_es.pdf

Comisión Económica para América Latina y el Caribe (CEPAL). (2020b). Sectores y empresas frente al COVID-19: emergencia y reactivación. https://repositorio.cepal.org/bitstream/handle/11362/45734/4/S2000438_es.pdf

Cordero, G., Segarra, E. V., Correa, C., y Rodríguez, N. (2019). Apoyos y obstáculos para el desarrollo de microempresas: percepción de sus dueños. Fórum Empresarial, 24(1), 55-95. https://revistas.upr.edu/index.php/forumempresarial/article/view/17230

Correa, F., Leiva, V., y Stumpo, G. (2018). Mipymes y heterogeneidad estructural en América Latina. Comisión Económica para América Latina y el Caribe (CEPAL), October, 13-44. https://www.researchgate.net/publication/328314810_Mipymes_y_heterogeneidad_estruc tural_en_America_Latina

Davalos, X., y Jimeno, J. F. (s. f.). Credibilidad de la Política Fiscal en el Ecuador [Tesis Doctoral, Universidad de Alcalá]. https://www.educacion.gob.es/teseo/imprimirFicheroTesis.do?idFichero=QFNd9Fa0nlE $\% 3 \mathrm{D}$

Díaz, S. (2010). La Microempresa en el Desarrollo. Perspectivas, 25, 271-282. https://www.redalyc.org/pdf/4259/425942454014.pdf

Dini, M., y Stumpo, G. (2018). MIPYMES en América Latina Un frágil desempeño y nuevos desafíos para las políticas de fomento. En Comisión Económica para América Latina y el Caribe (CEPAL). https://www.cepal.org/es/publicaciones/44148-mipymes-america- 
latina-un-fragil-desempeno-nuevos-desafios-politicas-fomento

Endara, M. S., y Villacís, J. F. (2018). RISE 10 años de vigencia Evolución, desafíos y perspectivas [Tesis de Maestría en Tributación, Universidad Andina Simón Bolívar]. https://repositorio.uasb.edu.ec/bitstream/10644/6485/1/T2788-MT-Endara-Rise.pdf

Mejía-Flores, O. G., Pino-Jordán, R., y Parrales-Choez, C. G. (2019). Políticas tributarias y la evasión fiscal en la República del Ecuador. Aproximación a un modelo teórico. Revista Venezolana De Gerencia, $24(88), \quad 1147-1165$. https://doi.org/10.37960/revista.v24i88.30169

Hernández, P., Ramírez, G., Pérez, R., y Molina, N. (2019). Financiamiento de los microempresarios del Centro Comercial Popular El Salto, Latacunga, Ecuador. Espacios, 40, 26. https://www.revistaespacios.com/a19v40n22/a19v40n22p26.pdf

Herrera, H. V. (2015). Complementariedad de las inversiones a largo plazo y de capital de trabajo ante oportunidades de negocios y consideraciones de liquidez en países latinoamericanos. Estudios Gerenciales, 31(137), 364-372. https://www.redalyc.org/pdf/212/21243557002.pdf

Honorable Congreso Nacional, L. C. de L. y C. (2019). Ley de Régimen Tributario Interno, LRTI. https://bit.ly/3qH2rtK

Instituto Nacional de Estadísticas y Censos. (2018). Visualizador de Estadístias Productivas. Directorio de Empresas. https://bit.ly/3zq7537

Instituto Nacional de Estadísticas y Cesos. (2019). Directorio de Empresas y Establecimientos 2018. https://bit.ly/32HazCJ

Junta de Política y Regulación Monetaria y Financiera. (2015). Resolución No. 043-2015-F. www.bce.edu.ec. https://www.bce.fin.ec/images/junta/Resolucion No. 043-2015F.pdf?dl=0MonFin/TasasInteres/RegTasas043.pdf

La Asamblea Constituyente. (2007). Ley Reformatoria para la Equidad Tributaria del Ecuador. 1-113. https://www.gob.ec/sites/default/files/regulations/2020-02/Ley Reformatoria para la Equidad Tributaria.pdf

Levy, N. (2013). Reforma financiera y banca de desarrollo: créditos o ilusiones. Economía Informa, 382, 3-17. https://doi.org/10.1016/S0185-0849(13)71332-X

Martínez Cuellar, C. (2013). El efecto de la desigualdad y el acceso al crédito sobre la acumulación de capital humano. Ensayos sobre Política Económica, 31(72), 18-34. https://doi.org/10.1016/S0120-4483(13)70002-2

Nacata, H. M., y Monge, J. F. (2021). Régimen impositivo para microempresas y su incidencia en el cálculo del impuesto a la renta: caso DISPROALCEX S.A. Revista Eruditus, 2(3), 2940. https://doi.org/10.35290/re.v2n3.2021.507

Primicias. (2020). Recaudación de impuestos bajó $17 \%$ en el primer semestre de 2020. https://www.primicias.ec/noticias/economia/recaudacion-impuestos-caida-primersemestre/

Ramírez, N., y Guevara, D. (2021). Las microfinanzas rurales en Colombia y el proceso de financiarización: un estudio de caso. Apuntes del CENES, 40 (71), 219-252. https://revistas.uptc.edu.co/index.php/cenes/article/view/11466

Rivera, A. M., y Cardozo, J. R. (2019). Impacto del microcrédito en el mercado central de Tarija. 18, 177-200. http://www.scielo.org.bo/pdf/rfer/v18n18/v18n18_a10.pdf

Salcedo, J., y Ortega, S. (2020). Incidencia de los Beneficios Tributarios en el Pago del Impuesto a la Renta de las Microempresas del sector de Servicios Zona 8 del Ecuador [Tesis de 
Maestría, Universidad Politécnica Salesiana Ecuador]. https://dspace.ups.edu.ec/bitstream/123456789/19630/4/UPS-GT003090.pdf

Sampieri, R., Fernánez, C., y Baptista, P. (2014). Metodología de la Investigación. http://observatorio.epacartagena.gov.co/wp-content/uploads/2017/08/metodologia-de-lainvestigacion-sexta-edicion.compressed.pdf

Servicio de Rentas Internas. (2019). Estadísticas Generales de Recaudación SRI. https://www.sri.gob.ec/estadisticas-generales-de-recaudacion-sri

Servicio de Rentas Internas. (2020). Catastro del Régimen Impositivo para Microempresas. Catastro del Régimen Impositivo para Microempresas. https://www.sri.gob.ec/web/guest/catastros

Servicio de Rentas Internas. (2021). Régimen Impositivo Simplificado. https://www.sri.gob.ec/regimen-impositivo-simplificado-rise\#requisitos

Sumba, R., y Santistevan, K. (2018). Las Microempresas y la Necesidad de Fortalecimiento: Reflexiones de la zona Sur de Manabí, Ecuador. Universidad y Sociedad, 10(3), 134-141. http://scielo.sld.cu/pdf/rus/v10n5/2218-3620-rus-10-05-323.pdf

Texis, M., Ramírez, M., y Aguilar, J. (2016). Microempresas de base social y sus posibilidades de supervivencia. Contaduria y Administracion, 61(3), 551-567. http://www.scielo.org.mx/pdf/cya/v61n3/0186-1042-cya-61-03-00551.pdf

Urdaneta, A. J., Romero, M. A., y Mejía, O. G. (2020). Hechos Estilizados del Ahorro, Crédito y Crecimiento Económico Regionales del Ecuador. Polo de Conocimiento, 5(09), 254-280. https://dialnet.unirioja.es/servlet/articulo?codigo $=7554417$

Valentin Mballa, L. (2017). Desarrollo local y microfinanzas como estrategias de atención a las necesidades sociales: un acercamiento teórico conceptual. Revista Mexicana de Ciencias Politicas y Sociales, 62(229), 101-127. http://www.scielo.org.mx/scielo.php?pid=S0185$19182017000100101 \&$ script=sci_abstract

Vásquez-Salinas, J. (2011). Ecuador, microcrédito: ¿Negocio o inclusión financiera? Retos. Revista de Ciencias de la Administración y Economía, 1(2), 39-47. https://doi.org/10.17163/ret.n2.2011.06

Zanzzi, F., Cordero, A., y Cordero, M. (2016). Reformas tributarias modeladas con vectores autoregresivos: Caso Ecuador. Economía, XLI, 53-75. https://www.redalyc.org/articulo.oa?id=195650099003 